\title{
Prospects and challenges: inhalation delivery systems
}

\author{
"The goal of an inhalation delivery system should be to ensure that the patient will consistently receive the prescribed \\ medication and adhere to therapy."
}

Keywords: aerosol $₫$ dry powder inhaler $₫$ lung $₫$ metered-dose inhaler $\approx$ nebulizer

There have been extraordinary advances in device technology and performance over the last 30 years [1-3]. Despite these improvements, delivering drugs effectively by inhalation therapy remains a significant challenge. The goal of an inhalation delivery system should be to ensure that the patient will consistently receive the prescribed medication and adhere to therapy. Ultimately though, as with any self-administered medication, the projected therapeutic benefit is at the mercy of the patient. Furthermore, the patient is not the only stakeholder invested in the performance and use of a delivery system. The developer, regulator and prescriber all influence the therapeutic outcome. This article discusses the convoluted genesis of inhalation delivery systems from the view of the aforementioned stakeholders and gives consideration to what the future may hold for these devices.

\section{No 'one-stop' solution}

The diverse range of devices and technologies in use reflect that no single, drug-device 'solution' satisfies the needs of all patients.

\section{- Nebulizers}

Conventional devices such as jet nebulizers are in general use for solution-/suspension-based drugs, but in recent years these devices have become more frequently associated with specific medication. They remain inexpensive and increasingly portable (e.g., lightweight battery-driven units) but despite many incremental improvements, they remain inefficient, cumbersome and generally require lengthy delivery times (10-30 min), all factors that negatively impact adherence. Nevertheless, they are the delivery systems of choice for high-dose therapeutics and for patient groups who struggle using alternatives (or where no alternative exists).

More sophisticated and expensive extensions of the nebulizer platform, such as the mesh-based devices, strive to deliver medication more rapidly and/or more efficiently in an effort to reduce drug waste and improve patient convenience [4]. There are also unique systems such as the Respimat ${ }^{\circledR}$ (Boehringer Ingelheim, Germany) that compete with propellant-driven metered-dose inhalers (pMDIs) for bolus dosing needs.

\section{- pMDIs}

These inhalers wonderfully satisfy the need for portability and convenience but are largely limited to relatively inexpensive and potent small molecules that can be appropriately formulated in propellants. These devices have improved but are inherently inefficient, actuation must be timed correctly and significant oropharyngeal deposition occurs when used without spacer devices [5].

\section{- Dry powder inhalers}

The early dry powder inhaler devices provided for bolus administration, however like the pMDIs, they were woefully inefficient and highly variable in terms of performance (10-30\% lung deposition of nominal dose). However, the combination of dry powder inhaler and particle engineering has markedly improved delivery efficiency $(50-70 \%)$, although few such 'designer combinations' have yet been brought to the market.

The above device offerings are functionally different in terms of use and performance; however, there is no real 'winner' and the weight of evidence indicates that adherence to therapy is generally poor, with only $30-50 \%$ of patients using devices correctly and thus consistently receiving adequate medication [6-8].

\section{Patients}

The most sophisticated and efficient delivery system is wasted if the patient cannot or will not

\section{Ralph Niven}

Novartis, 150 Industrial Road, San Carlos, CA 94070, USA

Tel.: + 6506221729

E-mail: ralph.niven@novartis.com 
use it correctly [6]. Hence, the 'interface' of the delivery system with the patient is critical and often circumstance and psychology play as much of a role in dosing success as the functionality of the device [9]. An array of factors, some generic but often personal, will impact the outcome of the therapy. Out-of-pocket cost, size, handling, ease of use, dosing frequency, taste of inhaled medication, expectation of a response, general state of health, concomitant medication, support structure, training, education level and dexterity are some of the relevant factors [10]. Other nuanced personal factors will influence outcome. How comfortable are patients with their condition in public? How inconspicuous would they prefer their device to be? How familiar and comfortable are they with inhaler devices? What education and training has been provided to ensure compliance and to make them feel at ease? Perhaps they are using a range of inhaler medications that are all different. Which one is most important? Do they get confused with multiple inhalers? How many other medications do they take each day? Do they need family support or regular nursing support? How mobile are they (severe chronic obstructive pulmonary disease patients, for example, may suffer from a range of comorbidities). This litany of different issues and circumstances virtually guarantees that $100 \%$ adherence is impossible, so it becomes a question of how one best limits the consequences of noncompliance.

\section{Physicians}

Irrespective of whether a prescriber is a primarycare, emergency room or pulmonary physician, the relationship between the provider and the patient is again critical if therapeutic benefit is to be realized [11]. The caregiver's perception of the patient will drive the recommendation of a delivery system and heavily influence patient adherence $[9,12,13]$. For example, an elderly patient with dexterity problems may prefer a larger device where less reliance on coordination is needed [10]. This assumes, of course, that more than one device type is available for the therapy in question and that the prescriber is familiar with the choices. Indeed, will they be aware of the consequences on their patients of switching devices [14]? In all likelihood, a pulmonologist will have this experience but a busy family practice physician may not. The latter, after providing a diagnosis and prescription, may rely on other healthcare providers, such as the pharmacist to fill the knowledge gap. However, there is no guarantee that the 'trainers' have adequate knowledge of the available devices to teach correct use. In fact, various studies indicate that a cross-section of healthcare providers demonstrate competency at levels approaching that of their patients [15-18].

"... the 'interface' of the delivery system with the patient is critical and often circumstance and psychology play as much of a role in dosing success as the functionality of the device."

What is the setting in which the evaluation and training will be administered? Will it be a private room or a busy public environment? What recompense is the prescriber due from a payer for a given patient type and how easy is it for them to receive reimbursement (service or medication) [19]? In other words, how incentivized are they to provide the extra step in care-giving that may positively influence the outcome?

Sadly, consistency of care across all patient groups receiving inhalation therapy does not exist and without the necessary support networks (financial, educational, and so forth) in place, achieving clinical effectiveness will remain uneven $[6,18]$.

\section{- Pharmaceutical industry}

The end-user interface (patient-device and caregiver-patient) may not be a primary product design consideration in the early stages of development. Instead, factors such as potency, therapeutic index, physicochemical stability and projected dose regimen of the drug or drugs in question may govern the form factor of any coupled device [20]. Essentially, for the expected dosing needs, can the operating mechanism of the device satisfy the anticipated requirements? Is there any off-the-shelf/licensable device that is satisfactory or does the device have to be designed and engineered from scratch? Are the likely cost of goods, engineering and development requirements acceptable? Is the performance of the system acceptable? Are the materials compatible with the drug? Is the device reliable?

During early clinical development, the device may be modified but by Phase III clinical studies, the package should be finalized with the exception of cosmetic elements. Within this multitude of requirements, patient needs must also be considered and met alongside a corporation's desire for differentiation and revenue generation. 
Given the array of patient determinants that lead to an outcome, the optimal solution for an innovator would be to create an infinitely flexible delivery system such that it could be tailored to meet an individual's needs. In essence, meeting the ideal of 'personalized' medicine. However, such aspirations are at odds with current capabilities and even if the 'one-stop solution' existed, it would take many years to bring it to the market.

\section{Health authorities}

The mandate of the regulator is to provide assurance to the general public that the drug and device combination is safe, efficacious and production is adequately controlled. They are increasingly aware of the adherence and interface problems and engineering the human factor has become an important consideration in their review that must be satisfied by the innovator/sponsor in addition to standard requirements. Moreover, for each innovator device product that tests the boundaries of established guidelines, there is a new learning curve associated with submitted documentation and thus it is not surprising that lengthy review times are the norm.

\section{What does the future hold?}

Predicting the future of inhalation devices is a risky exercise. On the technical side, it is reasonable to suggest that improved feedback mechanisms will be incorporated in to device systems. What is not clear is how far this can be pursued. Simple elements such as mechanical dose counters and light-emitting diodes are already in use, but more attention will likely be paid to what dose a patient receives and not just whether they actuated a device. An extension of feedback includes 'telehealth' wherein realtime or periodic information will be reported to the caregiver [21]. However, such monitoring efforts bring up ethical and legal questions concerning privacy $[22,23]$. Furthermore, the extent to which such e-monitoring systems are employed in clinical studies may impact a sponsor's ability to commercialize a system without the e-monitoring $[24,25]$. However, we can certainly expect to see far more attention paid to the patient-device interface in an effort to address the adherence problem.

Another emerging question is one of interchangeability within proprietary devices, particularly capsule-based devices. This is an aspect of the bigger question of device diversity and a patient's ability to remain adherent to multiple delivery systems. Can innovators look beyond managing the tortuous development pathway for their own system while ensuring incompatibility with others? This is a potential safety concern that has received regulator attention. However, does designing incompatibility for safety reasons introduce radically different learning curves for each medication that a patient may be using, such that adherence is further compromised? Furthermore, how far can health authorities hope to pursue safety before compromising efficacy?
“... the optimal solution for an innovator would be to create an infinitely flexible delivery system such that it could be tailored to meet an individual's needs."

At the socioeconomic level, devices may be impacted by the insidious 'cost-of-life' question: an issue that aging societies cannot continue to neglect. Within the USA, there is political pressure to rein in entitlement programs (Medicare and Medicaid). Healthcare cost increases that outpace inflation are unacceptable and, by various measures, inhalation therapies will likely have to demonstrate zero increase in healthcare burden and/or a positive benefit to society. Educational and training initiatives will also likely have to find similar cost justifications. This all suggests that highly sophisticated and expensive delivery systems will have difficulty finding a niche within the inhalation system armamentarium unless that sophistication can be amortized across a large number of doses. However, pragmatic innovators will recognize these trends and pursue ways to develop inexpensive and functional devices, in a setting where limited reimbursement and higher out-of-pocket expense for the patient is inevitable.

\section{Acknowledgments}

The author wishes to thank A Clark, D Miller and D Maltz for reviewing and contributing to the text.

Financial \& competing interests disclosure The author is an employee of Novartis. The author has no other relevant affiliations or financial involvement with any organization or entity with a financial interest in or financial conflict with the subject matter or materials discussed in the manuscript apart from those disclosed.

No writing assistance was utilized in the production of this manuscript. 


\section{References}

1 Fischer A, Stegemann J, Scheuch G, Siekmeier R. Novel devices for individualized controlled inhalation can optimize aerosol therapy in efficacy, patient care and power of clinical trials. Eur. J. Med. Res. 14(Suppl. 4), 71-77 (2009).

2 Friebel C, Steckel H. Single-use disposable dry powder inhalers for pulmonary drug delivery. Expert Opin. Drug Deliv. 7(12), 1359-1372 (2010).

3 Yeo LY, Friend JR, McIntosh MP, Meeusen EN, Morton DA. Ultrasonic nebulization platforms for pulmonary drug delivery. Expert Opin. Drug Deliv. 7(6), 663-679 (2010).

4 Watts AB, Mcconville JT, Williams RO 3rd. Current therapies and technological advances in aqueous aerosol drug delivery. Drug Dev. Ind. Pharm. 34(9), 913-922 (2008).

5 Bell J, Newman $S$. The rejuvenated pressurised metered dose inhaler. Expert Opin. Drug Deliv. 4(3), 215-234 (2007).

6 Crompton GK, Barnes PJ, Broeders M et al. The need to improve inhalation technique in Europe: a report from the Aerosol Drug Management Improvement Team. Respir. Med. 100 (9), 1479-1494 (2006).

7 Melani AS, Bonavia M, Cilenti V et al. Inhaler mishandling remains common in real life and is associated with reduced disease control. Respir. Med. 105(6), 930-938 (2011).

8 Rau JL. Determinants of patient adherence to an aerosol regimen. Respir. Care 50(10), 1346-1356; discussion 1357-1349 (2005).

9 Madoc-Sutton H, Hardy A, Fletcher M, Walker S. Assessment of key influences on asthma inhaler device selection. Nurs. Stand. 23(24), 35-41 (2009).
10 Barrons R, Pegram A, Borries A. Inhaler device selection: special considerations in elderly patients with chronic obstructive pulmonary disease. Am. J. Health Syst. Pharm. 68(13), 1221-1232 (2011).

11 Ari A, Fink JB. Guidelines for aerosol devices in infants, children and adults: which to choose, why and how to achieve effective aerosol therapy. Expert Rev. Respir. Med. 5(4), 561-572 (2011).

12 Melani AS. Inhalatory therapy training: a priority challenge for the physician. Acta Biomed. 78(3), 233-245 (2007).

13 Dolovich MB, Ahrens RC, Hess DR et al. Device selection and outcomes of aerosol therapy: evidence-based guidelines: American College of Chest Physicians/American College of Asthma, Allergy, and Immunology. Chest 127(1), 335-371 (2005).

14 Doyle S, Lloyd A, Williams A et al. What happens to patients who have their asthma device switched without their consent? Prim. Care Respir. J. 19(2), 131-139 (2010).

15 Hanania NA, Wittman R, Kesten S, Chapman KR. Medical personnel's knowledge of and ability to use inhaling devices. Metered-dose inhalers, spacing chambers, and breath-actuated dry powder inhalers. Chest 105(1), 111-116 (1994).

16 Kim SH, Kwak HJ, Kim TB et al. Inappropriate techniques used by internal medicine residents with three kinds of inhalers (a metered dose inhaler, Diskus, and Turbuhaler): changes after a single teaching session. J. Asthma 46(9), 944-950 (2009).

17 Chopra N, Oprescu N, Fask A, Oppenheimer J. Does introduction of new "easy to use" inhalational devices improve medical personnel's knowledge of their proper use? Ann. Allergy Asthma Immunol. 88(4), 395-400 (2002).

18 Fink JB, Rubin BK. Problems with inhaler use: a call for improved clinician and patient education. Respir. Care 50(10), 1360-1374; discussion 1374-1365 (2005).

19 Sims MW. Aerosol therapy for obstructive lung diseases: device selection and practice management issues. Chest 140(3), 781-788 (2011).

20 Islam N, Cleary MJ. Developing an efficient and reliable dry powder inhaler for pulmonary drug delivery - a review for multidisciplinary researchers. Med. Eng. Phys. 34(4), 409-427 (2012).

21 Daniels T, Goodacre L, Sutton C, Pollard K, Conway S, Peckham D. Accurate assessment of adherence: self-report and clinician report vs electronic monitoring of nebulizers. Chest 140(2), 425-432 (2011).

22 Clark PA, Capuzzi K, Harrison J. Telemedicine: medical, legal and ethical perspectives. Med. Sci. Monit. 16(12), RA261-RA272 (2010).

23 Demiris G, Doorenbos AZ, Towle C. Ethical considerations regarding the use of technology for older adults. The case of telehealth. Res. Gerontol. Nurs. 2(2), 128-136 (2009).

24 Dicarlo LA. Role for direct electronic verification of pharmaceutical ingestion in pharmaceutical development. Contemp. Clin. Trials 33(4), 593-600 (2012).

25 Foster JM, Smith L, Usherwood T, Sawyer SM, Rand CS, Reddel HK. The reliability and patient acceptability of the SmartTrack device: a new electronic monitor and reminder device for metered dose inhalers. J. Asthma 49(6), 657-662 (2012). 